ISBN 978-81-933894-1-6

International Conference on Studies in Disaster Management, Civil and Architectural Engineering

(SDMCAE-17)

Kyoto (Japan) April 18-19, 2017

\title{
Japanese Metropolitan Structure through Correlated Demographics and Local High Education and Research
}

\author{
Aurelia Stan and Atsushi Deguchi \\ Department of Socio-cultural Environmental Studies, \\ Graduate School of Frontier Sciences, \\ The University of Tokyo, Japan
}

\begin{abstract}
The recent transition to a post-industrial society together with the communication revolution started a process of redistribution of economic centres within metropolitan areas. In a continuous urbanisation process, most significant urban growth occurs in the metropolitan margin. Thus the metropolis develops into a polycentric mass where physical boundaries lose significance allowing for an increase in flexibility. Areas outside city cores gain stronger urban character and become essential in regional development networks. The new relationships established between central cities and their metropolitan areas are of partnership rather than subordination, partnership which is now essential for urban competitiveness. As this partnership continues to evolve, the boundary between urban and suburban dissolves allowing for urban employment, services and spatial typologies to dissipate throughout metropolitan areas, generating networks. Since knowledge has replaced goods as the main economic product, knowledge networks are amongst the most significant in metropolitan development. Post industrialisation of metropolitan peripheries in a polycentric pattern occurs in Japan in the particular context of population ageing and decline. This phenomenon, also known as shrinkage, impacts service provision, infrastructure and the urban fabric as a whole through economic decline and decreasing densities. Through statistical analysis, this paper investigates the correlation between local higher education and research employment provision, and recent population evolution, in the two largest major metropolitan areas in Japan: Tokyo and Keihanshin. Furthermore, the paper identifies, within the studied metropolitan areas, areas where knowledge production is most intense correlated with population growth. The study is meant as a possible basis for further metropolitan restructuring that can address population and urban shrinkage issues
\end{abstract}

Keywords: population decline, post-industrial, metropolitan structure, Tokyo, Keihanshin

\section{Introduction}

The concept of post-industrialisation was first used by French sociologist Alain Tourainne in 1969 but popularised 4 years later by Daniel Bell's book "The Coming of Post-industrial Society". The concept was needed to define the significant changes that appeared in developed economies after the Second World War, changes that both authors agree to being rooted in the change in demand from goods to services. (Bell [1])

Simultaneous with this major change to an ever increasing demand for complex services rather than goods, knowledge and implicitly knowledge production gains a new crucial role in advanced economies. (Tourraine [2]) If we list Bell's 4 essential traits of the post-industrial society: (1) theoretical knowledge is central, (2) new "intellectual" technology is created, (3) growth of a new class based on knowledge and (4) shift from goods to services we can see that 3 out of 4 refer to knowledge as central to new economic and social changes. (Bell [1]) "It would be an understatement to suggest that knowledge plays a key role in today's economy; for much of the developed world, it might be more accurate to assert that knowledge is today's economy."(Gabe, Abel, Ross and Stolarick [3]) In this knowledge centric world, universities are hosts for both knowledge creation and 
distribution and become attractive as catalysts of cluster formation, as in the case of Stanford University, essential attraction pole in Sillicon Valley.

The manifestations of post-industrialisation in an urban context are complex, shaping new urban structures. Liberated from mass production and assembly lines and no longer labour intensive (Phelps [4]), employment centres can now disperse following availability of land and low prices and leading to polycentric metropolitan structures with economic cores in the periphery as well as in the traditional CBDs. (Hall and Pain [5]) Now, peripheral metropolitan networks include employment centres, often clustered around knowledge production activities, that are no longer subdued to the traditional dependence on the city core.

In Japan, this process of conversion of metropolises intro polycentric metropolitan regions (Hall and Pain[5]) is supported by the traditional structure of the Japanese city that developed through sprawl to include multiple local centres (Hidenobu [6]) that were later enhanced by the railway network. In opposition to this favourable context comes the recent government support for inner city repopulation through building high rise apartment buildings and increasing availability of housing in city cores. (Sorensen[7])

Another essential factor that determines the evolution of Japanese metropolitan areas is the recent decline and ageing of the population. (Sorensen [7]) Population shrinking or decline is a phenomenon that has manifested around the world as a direct consequence of economic change. Rural areas were the first to suffer this consequence within the process of industrialisation which acted as a catalyst for urban growth, while he transition from the industrial to the post-industrial stage caused shrinkage in industrial cities. In both this cases, population decline was a localised phenomenon, in contradiction with the overall population growth, and is mostly generated by out-migration. (Matanle and Rausch[8])

On the other hand, population ageing is relatively new and can be found mostly in countries with advanced economies that have a death rate higher than the birth and in-migration rates. This phenomenon can be assessed in a regional context, but is most frequently discussed at a national level. Japan is one of the countries with the highest ageing population rate in the world.

\section{Purpose}

This study is intended as a starting point for the metropolitan restructuring made necessary by the current population ageing and decline. Decreasing densities lead to ever more unsustainable physical and service infrastructures and can cause isolation in more remote areas. In such a context, urban planning and design must begin a metropolitan spatial restructuring process that will tackle would tackle the density issues. Identifying areas that have correlated knowledge production and growth can serve as a basis for future urban public policy.

\section{Objectives}

To establish a correlation between local higher education and research activities and population growth and a lower median age.

To define, based on higher education and research activities as well as population evolution, possible development regions within Tokyo and Keihanshin metropolitan areas.

\section{Data and Methodology}

\subsection{Study Area}

The object of this study are the biggest Major Metropolitan Areas (MMA) in Japan: Tokyo and Keihanshin. The Statistics Bureau of Japan defines a metropolitan area as one or more core cities together with all the surrounding municipalities with at least $1.5 \%$ of the workforce commuting to a core city. Despite not meeting this criterion, a municipality will become a part of the metropolitan area if it is surrounded by municipalities that are already included. In order to become Major Metropolitan Area, a metropolitan area has to include one or more core cities with a designated city statute, which is given through government ordinance to cities with a population larger than 500000 . 
The study area includes 350 municipalities: Tokyo MMA consists of 218 municipalities out of which 28 are designated metropolitan cores (23 Tokyo Special Wards, Yokohama, Kawasaki, Sagamihara, Chiba City and Saitama City). Keihanshin MMA consists of 132 municipalities out of which 4 are designated metropolitan cores (Osaka, Kyoto, Kobe and Sakai).

\subsection{Data}

As there is no centralised data regarding universities in Japan, this study used the Jasso list of universities in Japan to identify all the universities with campuses located in the studied metropolitan areas. As this study is trying to correlate population evolution and age with knowledge production and not just higher education, only universities that offer graduate programs were included. The data concerning the number of students and university academic personnel were obtained from the mandatory public information chapter from the website of each university. The study considered a total number of 338 university campuses from 228 universities out of which 145 universities with 236 campuses in Tokyo MMA and 83 universities with 102 campuses in Keihanshin MMA.

Since research activities in Japan are not exclusive to universities, this study used also local research employment data which, together with population evolution and age data, was retrieved for each municipality from the website of the Statistics Bureau of Japan as follows: research employment data from the 2009 Economic Census, population evolution data from the 2015 Census and median age data from the 2010 Census as the results of the 2015 Census were not all made public at the time tis study was conducted. Since not universities publish historical statistics, the data used for this study was from 2015, with the assumption that it does not differ significantly from the 2009 data, since no new campuses have been opened after 2009.

\subsection{Methodology}

Through a metha-synthetic literature review, this study introduces the concept of post-industrialisation and the transition in production from goods to services and knowledge.

Quantitative research, specifically correlation and regression analysis were used to assess the significance of the relation between local high education and research activities and both population evolution and population age. All statistical analyses were performed using SPSS.

Combined quantitative and qualitative research were used for the purpose of spatially defining within the studied metropolitan areas regions that show significant high education and research activities and population growth. Municipalities that include university campuses or a research employment ratio higher than the minimum ratio among the metropolitan cores were considered as having significant knowledge production activities.

\section{Knowledge Production and Demographic Change}

Multiple regression analyses were performed in order to assess the significance of the correlations between population evolution between 2010 and 2015 and median age as dependent variables and: (1) number of local campuses, (2) undergraduate students ratio 2015, (3) postgraduate students ratio 2015, (4) foreign students ratio 2015, (5) full-time academic personnel ratio 2015, (6) local research employment ratio 2009 as independent variables or predictors.

The number of campuses and the undergraduate students ratio were considered for assessing the size of the higher education institutions at a local level, while the foreign student ratio addresses the diversity of the institutions and the number of graduate students and faculty members attempt to quantify the research activities that take place within. Since research activities in Japan are not limited to the academic environment, this study also considers local research employment ratio, which is an indicator meant to include research activities that take place in research institutes, think tanks or even the private sector.

Out of the 6 independent variables, some may appear to be collinear, more specifically the undergraduate student ratio, postgraduate student ratio and full time faculty ratio. It might seem that a large university will have 
all three ratios higher than a small one, when in reality, in the studied metropolitan areas there are examples of very large universities that focus almost exclusively on undergraduate education as well as strictly postgraduate universities. Also, depending on the university profile, the full time faculty ratio can vary greatly. For example, medical sciences universities have a significantly higher ratio of academic personnel. Regardless of these examples, multicollinearity test was performed, and the results are showed in table 1. The results show that, except for the case of Keihanshin MMA where the undergraduate student ratio is collinear with the full time faculty ratio, all the other indicators are not collinear since all the values are lower than 0.7 . As a consequence of this, the regression analysis for Keihanshin MMA was performed with only 5 predictors, excluding the full time faculty ratio.

$$
\begin{aligned}
& \mathrm{Pev}=\text { population evolution }=(\text { population } 2015-\text { population } 2010) * 100 / \text { population } 2010 \\
& \mathrm{Ma}=\text { median age } \\
& \mathrm{Cn}=\text { number of campuses } \\
& \mathrm{Ru}=\text { undergraduate students ratio }=\text { number of undergraduate students } * 100 / \text { total population } \\
& \mathrm{Rp}=\text { postgraduate students ratio }=\text { number of postgraduate students } * 100 / \text { total population } \\
& \mathrm{Ri}=\text { international students ratio }=\text { number of foreign students } * 100 / \text { total number of students } \\
& \mathrm{Rf}=\text { faculty ratio }=\text { full-time faculty number } * 100 / \text { total population } \\
& \mathrm{Rem}=\text { local research employment ratio }=\text { number of local research jobs } * 100 / \text { number of local jobs }
\end{aligned}
$$

Table I: Multicollinearity Test Results

\begin{tabular}{|l|l|l|l|l|l|l|l|l|l|l|l|l|l|l|l|l|}
\hline \hline \multicolumn{10}{|c|}{ Tokyo MMA } & \multicolumn{10}{|c|}{ Keihanshin MMA } \\
\hline & Pev & Ma & Cn & Ru & Rp & Ri & Rf & Rem & Pev & Ma & Cn & Ru & Rp & Ri & Rf & Rem \\
\hline \hline Pev & 1.00 & - & 0.47 & 0.40 & 0.29 & 0.24 & 0.06 & 0.34 & 1.00 & - & 0.18 & 0.14 & 0.19 & 0.22 & 0.10 & 0.39 \\
\hline Ma & - & 1.00 & - & - & - & - & - & - & - & 1.00 & - & - & - & - & - & -0.31 \\
\hline $\mathrm{Cn}$ & 0.47 & - & 1.00 & 0.49 & 0.37 & 0.37 & 0.21 & 0.20 & 0.18 & - & 1.00 & 0.26 & 0.23 & 0.36 & 0.23 & 0.12 \\
\hline $\mathrm{Ru}$ & 0.40 & - & 0.49 & 1.00 & 0.10 & 0.13 & 0.10 & 0.16 & 0.14 & - & 0.26 & 1.00 & 0.10 & 0.40 & 0.92 & -0.07 \\
\hline $\mathrm{Rp}$ & 0.29 & - & 0.37 & 0.10 & 1.00 & 0.51 & 0.16 & 0.23 & 0.19 & - & 0.23 & 0.10 & 1.00 & 0.32 & 0.19 & 0.04 \\
\hline $\mathrm{Ri}$ & 0.24 & - & 0.37 & 0.13 & 0.51 & 1.00 & 0.63 & 0.20 & 0.22 & - & 0.36 & 0.40 & 0.32 & 1.00 & 0.32 & 0.04 \\
\hline $\mathrm{Rf}$ & 0.06 & - & 0.21 & 0.10 & 0.16 & 0.63 & 1.00 & 0.07 & 0.10 & - & 0.23 & 0.92 & 0.19 & 0.32 & 1.00 & -0.08 \\
\hline $\mathrm{Rem}$ & 0.34 & - & 0.20 & 0.16 & 0.23 & 0.20 & 0.07 & 1.00 & 0.39 & - & 0.12 & - & 0.04 & 0.04 & - & 1.00 \\
\hline \hline
\end{tabular}

\subsection{Declining Population}

In order to assess the relation between population evolution and local high education and research activities, multiple regression analyses were performed for both Tokyo and Keihanshin MMA using population evolution between 2010 and 2015 as dependent variable. The independent variable as well as the results of the analyses are shown in Table 2.

Tokyo MMA: According to the correlation coefficients p, all predictors are significantly correlated at $99 \%$ level with the evolution of the population, the only exception being faculty ratio, which shows no correlation. The analysis overall is also highly significant at the $99 \%$ level, but the predictions are significant only for the number of campuses, undergraduate student ratio and research employment ratio. The Rsq value shows that variations in the predicted indicators can be correlated with $33 \%$ variation in population evolution values. Considering only the indicators for which the analysis is significant, from the B values we deduce that an increase in the number of campuses by one can be correlated with a $6,7 \%$ growth in population, increasing by $1 \%$ the research employment ratio can be correlated with $3.8 \%$ increase of population and increasing the undergraduate student ratio per population by $1 \%$ can be correlated with $0.9 \%$ increase in population. All population increases are predicted to take place within a timeframe of 5 years. 
Table II: Regression Analysis Results. Dependent Variable: Population Evolution

\begin{tabular}{|c|c|c|c|c|c|c|c|c|c|c|c|c|c|c|}
\hline & \multicolumn{7}{|c|}{ Tokyo MMA } & \multicolumn{7}{|c|}{ Keihanshin MMA } \\
\hline & $\mathrm{p}$ & $\mathrm{R}$ & Rsq & ANOVA sig & B & $\mathrm{t}$ & tsig & $\mathrm{p}$ & $\mathrm{R}$ & Rsq & ANOVA sig & B & $\mathrm{t}$ & tsig \\
\hline $\mathrm{Cn}$ & 0.000 & \multirow{6}{*}{0.575} & \multirow{6}{*}{0.330} & \multirow{6}{*}{0.000} & 0.671 & 3.957 & 0.000 & 0.022 & \multirow{4}{*}{0.470} & \multirow{4}{*}{0.221} & \multirow{4}{*}{0.000} & 0.041 & 0.455 & 0.650 \\
\hline $\mathrm{Ru}$ & 0.000 & & & & 0.092 & 3.256 & 0.001 & 0.060 & & & & 0.097 & 1.071 & 0.286 \\
\hline $\mathrm{Rp}$ & 0.000 & & & & 0.041 & 1.128 & 0.260 & 0.016 & & & & 0.122 & 1.404 & 0.163 \\
\hline $\mathrm{Ri}$ & 0.000 & & & & 0.150 & 1.053 & 0.294 & 0.007 & & & & 0.115 & 1.198 & 0.234 \\
\hline $\mathrm{Rf}$ & 0.171 & & & & -0.454 & -1.341 & 0.181 & I & I & I & 1 & I & 1 & 1 \\
\hline $\mathrm{R}$ & 0.000 & & & & 0.381 & 3.674 & 0.000 & 0.000 & 0.470 & 0.220719 & 0.000018 & 0.383 & 4.633 & 0.000 \\
\hline
\end{tabular}

The hypothesis that higher education and research activities are correlated with population evolution is proven correct, but higher education seems to be significant through size rather than academic research activities or diversity. The overall local research though shows a strong correlation with population evolution.

Keihanshin MMA: The analysis for Keihanshin MMA includes the same indicators as for Tokyo MMA, with the exception of faculty ratio which proved to be collinear with post graduate student ratio in the multicollinearity test. The reason for choosing to exclude the faculty ratio is that the values of this indicator can be considered as included in the local research employment ratio.

In the case of this metropolitan area, population evolution shows correlations significant at the $99 \%$ level with local research employment ratio and international student ratio and at the $95 \%$ level with postgraduate student ratio and number of campuses. The Rsq value shows that variations in the predicted indicators can be correlated with $22 \%$ variation in population evolution values, less than for Tokyo MMA. The analysis is, as in the case of Tokyo MMA, significant at the 99\% level, but the predictions are significant only for the local research employment ratio predictor. The B value in this case shows a correlation between an increase by $1 \%$ in the predictor's value and an increase of $3.8 \%$ in population over the course of 5 years. For Keihanshin MMA the only clearly significant correlation with population evolution can be proven only for local research employment and not for higher education activities

\subsection{Ageing Population}

Since currently Japan faces not only population decline but also ageing, the same multiple regression analysis was conducted, for both Tokyo and Keihanshin MMAs, using the same independent variables as in the previous subchapter, but with median age as dependent variable, in order to assess the relation between local higher education and research and population age. The results are shown in Table 3.

Tokyo MMA: In the case of population age, the correlation coefficient $\mathrm{p}$ show that median age is significantly negatively correlated with the number of campuses and local research employment ratios at the 99\% level and with the postgraduate student ratio at the $95 \%$ level. The analysis has very low significance, as variations in the predictors can be correlated with only 5\% change in median age. An Rsq value of 0.053 , lower than 0.2 , is indicative of a weak model. Predictions for all indicators have significance values much higher than 0.05, which makes all predictions in this model irrelevant for variations in the dependent variable, median age. 
Table III: Regression Analysis Results. Dependent Variable: Median Age

\begin{tabular}{|c|c|c|c|c|c|c|c|c|c|c|c|c|c|c|}
\hline & \multicolumn{7}{|c|}{ Tokyo MMA } & \multicolumn{7}{|c|}{ Keihanshin MMA| } \\
\hline & $\mathrm{p}$ & $\mathrm{R}$ & Rsq & $\begin{array}{l}\text { ANO } \\
\text { VA }\end{array}$ & B & $\mathrm{t}$ & tsig & $\mathrm{p}$ & $\mathrm{R}$ & Rsq & $\begin{array}{l}\text { ANO } \\
\text { VA }\end{array}$ & B & $\mathrm{t}$ & tsig \\
\hline $\mathrm{Cn}$ & 0.004 & \multirow{6}{*}{0.231} & \multirow{6}{*}{0.053} & \multirow{6}{*}{0.069} & -0.581 & -1.898 & 0.059 & 0.040 & \multirow{4}{*}{0.418} & \multirow{4}{*}{0.174} & \multirow{4}{*}{0.000} & -0.027 & -0.159 & 0.874 \\
\hline $\mathrm{Ru}$ & 0.204 & & & & 0.030 & 0.583 & 0.090 & 0.012 & & & & -0.153 & -1.755 & 0.082 \\
\hline $\mathrm{Rp}$ & 0.032 & & & & -0.020 & -0.299 & 0.560 & 0.036 & & & & -0.030 & -1.027 & 0.307 \\
\hline $\mathrm{Ri}$ & 0.065 & & & & -0.139 & -0.541 & 0.766 & 0.005 & & & & -0.264 & -1.188 & 0.237 \\
\hline $\mathrm{Rf}$ & 0.451 & & & & 0.472 & 0.771 & 0.589 & / & I & I & I & 1 & I & I \\
\hline $\mathrm{R}$ & 0.010 & & & & -0.310 & -1.706 & 0.441 & 0.000 & 0.4176 & 0.1744 & 0.0003 & -0.868 & -3.654 & 0.000 \\
\hline
\end{tabular}

Unlike the case of population evolution, the chosen indicators that represent local high education and research activities have proven to show no significant correlation with the overall age of the population.

Keihanshin MMA: Keihanshin MMA shows again results that differ considerably from Tokyo MMA. The correlation coefficients establish that the median age is significantly negatively correlated with research employment ratios and international student ratios at the $99 \%$ level and with number of campuses, undergraduate student ratio and postgraduate student ratio at the $95 \%$ level. The Rsq value, though lower than 0.2 does show that changes in the independent variables can be correlated with $17 \%$ variation in the predicted value. While the analysis is significant at the $99 \%$ level, the only significant prediction, as in the case of population evolution, is for local research employment ratio, in which an increase of $1 \%$ can be correlated with a decrease in median age with 0.8 years.

The hypothesis that local higher education and research can be negatively correlated with a lower population age is proven only for research activities and not for higher education.

\section{Spatial Structure}

Historically, unlike European cities that developed concentrically around a walled core, Japanese cities began their development through what we call today sprawl. City development on a large scale in Japan coincides with the industrial development that started in the Meiji era. Due to the scarcity of land, cities grew though absorbing numerous small, scattered rural settlements that later on transformed into urban nuclei giving Japanese cities the polycentric character that can be observed today. (Hidenobu [6]) This specific Japanese urban structure was later sustained by the development of a large rail network that insures mobility and could facilitate the transition to post-industrial typologies.

While Japan goes through a process of "recentralisation" meaning government policies that support inner city growth, there are still examples of employment centres being redistributed in the metropolitan periphery due to the flexibility of the "Information Age" or the local specific constraint of disaster prevention that requires lower densities. (Sato [9]) In the case of knowledge production, many important universities located in city cores have expanded in the periphery, sometimes supported by the government in the attempt to make commuting more feasible.

As universities and research facilities spread or even relocate, this study attempts to map the correlation between local research activities and population growth for the purpose of establishing possible development regions in future declining metropolitan areas.

Tokyo MMA the largest metropolitan area in Japan has, according to the 2015 census, a population of $37,309,327$ that, despite the overall country's decline, is still growing with an average of $1.43 \%$ in the interval 2010-2015. Even though on average the population is growing, only 95 municipalities exhibit growth while 123 are declining. Out of the 218 municipalities, 104 have a local research employment ratio higher than the minimum city core, proving that there is significant post-industrial development of the periphery. Tokyo MMA 
is home to 145 universities that meet this study's criteria and 246 campuses half of which are located outside city cores.

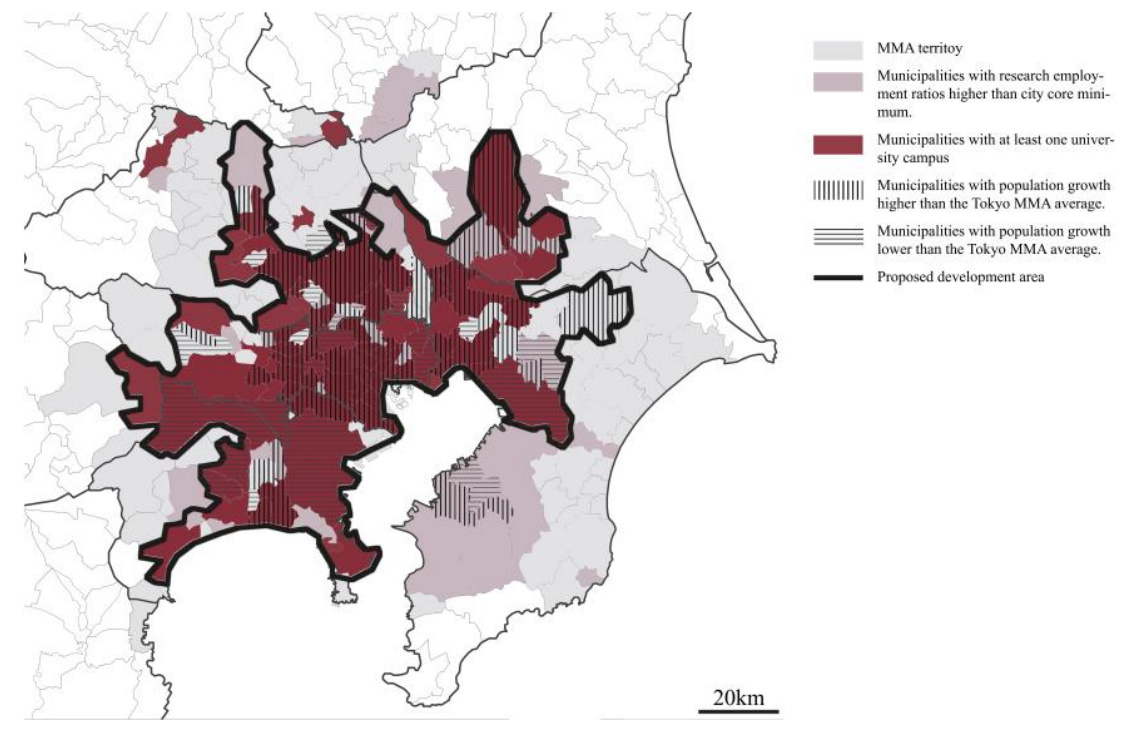

Fig. 1: Tokyo MMA. Local High Education and Research Activities and Population Evolution

Mapping the data used in the previous chapter, we can observe a dual circular radial pattern of the metropolitan area, possibly influenced by a strong city core formed by the 23 Special Wards of Tokyo, Yokohama and Kawasaki and a radial network of regional railways. Further development should follow this circular radial structure and should be concentrated in the areas that are already showing growth.

Keihanshin MMA is the second largest metropolitan area in Japan with a population of 19,253,418. According to the 2015 Census, the population declined by $0.46 \%$ between 2010 and 2015. Despite the overall decline, 38 municipalities in this metropolitan area still exhibit growth. In this metropolitan area, two of the four city cores, Kyoto and Kobe, have a declining population. Out of the 132 municipalities, 47 have a local research employment ratio, lower than the minimum pre city core exhibited by Sakai City. Keihanshin MMA is home to 83 universities with 102 campuses, out of which 63 are located outside city cores.

This metropolitan area has a triangular structure rooted in the spatial distribution of the metropolitan cores

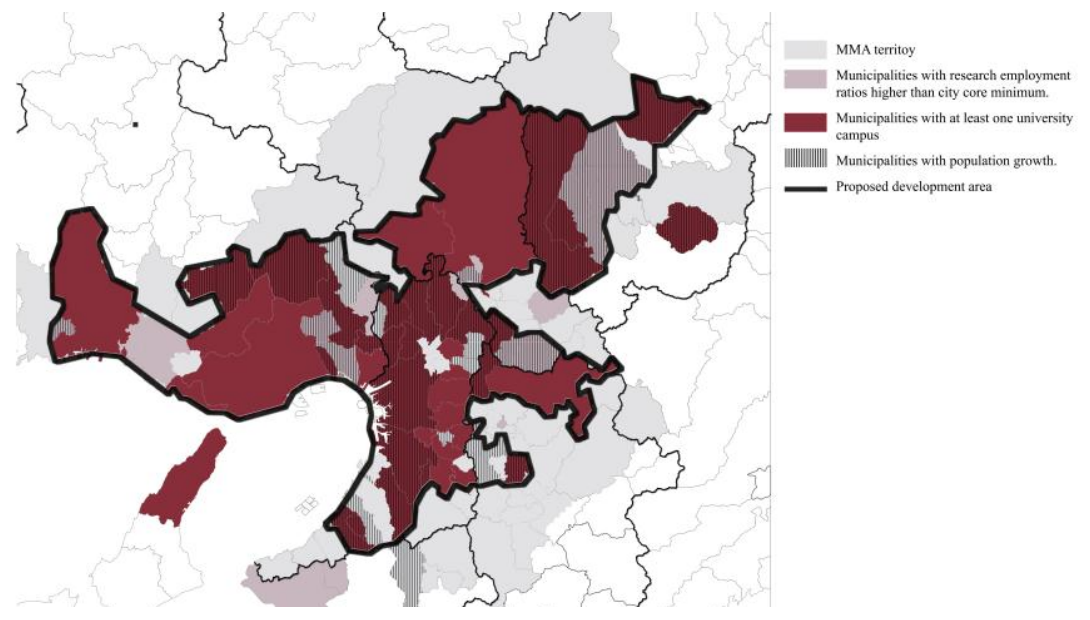

Fig. 2: Keihanshin MMA. Local High Education and Research Activities and Population Evolution

Osaka-Sakai, Kobe and Kyoto and supported by the secondary poles Nara and Wakayama. High local research 
employment ratios follow this triangular pattern, while the population growth regions are smaller and tend to avoid most Hyogo prefecture municipalities including Kobe City. Further development should be supported within this triangular pattern and especially encouraged in the Hyogo Prefecture municipalities including and adjacent to Kobe City as well as the city of Kyoto.

\section{Conclusions}

The hypothesis that local high education and research activities, implicitly knowledge production, is significantly correlated with population growth has been proven in the case of Tokyo MMA, while in Keihanshin MMA population growth is only correlated with research activities independently of their setting.

The hypothesis that the same local high education and research activities are negatively correlated with a lower median age could not be proven for Tokyo MMA and was proven with weak results for Keihanshin MMA. Overall, the relationship between local high education and research activities and population age is much less significant that than in the case of population evolution, thus it can be deduced that municipalities that include university campuses and have high local research employment ratios are highly attractive places that benefit from inward migration, without exhibiting demographic growth. Further research is needed to establish weather university campuses or a high local research employment is the cause for this attractiveness. The lack of correlation between population growth and lower median age, especially for municipalities that have large university campuses is rather counterintuitive and could be a consequence of the same attractiveness that could make them cost prohibitive for a younger population.

The spatial development structure of Tokyo MMA has a dual circular-radial structure based on the location of the city cores and the railway system. This structure is enhanced by the distribution of municipalities with

high ratios of high education and research activities that appear to follow the same pattern. Public policy should encourage further development along the existing trend.

Keihanshin MMA has a triangular structure, defined by the 4 metropolitan cores and enhanced by sub cores. While the municipalities with high ratios of research and high education activities also follow this triangular shape, population is declining in most of the Hyogo prefecture areas as well as the city of Kyoto. Further development should be encouraged not only in municipalities that exhibit population growth, but also in the declining areas within the triangular structure.

\section{References}

[1] D. Bell, The Coming of Post-industrial Society, Basic Books, New York, 1973.

[2] A. Tourraine, The Post-industrial Society. Tomorrow's Social History: Classes, Conflicts and Culture in the Programmed Society, Random House, New York, 1971

[3] T. Gabe, J. Abel, A. Ross and K. Stolarick, Knowledge in Cities, Urban Studies, 49(6) 1179-1200, May 2012

[4] N.A. Phelps, N. Parsons, D. Ballas and A. Dowling, Post-Suburban Europe: Planning and Politics at the Margins of Europe's Capital Cities, Palgrave McMillan, New York, 2006.

[5] P. Hall and K. Pain, The Polycentric Metropolis, Earthscan, UK and USA, 2006

[6] J. Hidenobu, Tokyo - A Spatial Anthropology, University of California Press, 1995

[7] A. Sorensen, Post-suburban Tokyo? Urbanization, Suburbanization, Reurbanization, in International Perspectives on Suburbanisation A Post-Suburban World?, Palsgrave Macmillan, New York, 2011

[8] P. Matanle and A. S. Rausch, Japan's Shrinking Regions in the 21st Century, Cambria Press, New York, 2011

[9] H. Satō, 東京大都市圈郊外の変化とオフィス立地.オフィス移転からみた業務核都市の姿, Tokyo, 2016 